\title{
El cronotopo patriarcal en el documental ¡Colombia Vive!
}

\author{
Franz Flórez ${ }^{* *}$
}

Recibido: 2 de marzo de 2014

\section{Resumen}

Evaluado: 24 de abril de 2014 Aceptado: 10 de mayo de 2014

Algo de historia y algo de justificación del presente se pueden rastrear en un documental, cuando la narración se organiza a partir de un cronotopo patriarcal. El conflicto en Colombia, contado de manera melodramática por Caracol y Semana, se convierte en un relato de aventuras donde la emoción surge de las acciones de confrontación armada, o de la búsqueda y captura de criminales, más que de indagar la lógica de relaciones premodernas que caracterizan a la sociedad colombiana, y que se expresan de manera violenta y no sólo servil.

Palabras clave: documental, cronotopo, Colombia, guerrilla, narcotráfico, paramilitares, sociedad señorial.

* Artículo de reflexión basado en la tesis de maestría (en curso) sobre la representación mediática del conflicto armado colombiano de las décadas de 1980 y 1990. Cómo citar este artículo: Flórez, F. (2014). El cronotopo patriarcal en el documental ¡Colombia Vive! Hallazgos, 11 (22), pp. 89-106.

** Docente del Departamento de Humanidades de la Universidad Jorge Tadeo Lozano, actualmente cursa la Maestría en Semiótica de la Universidad Jorge Tadeo Lozano (Colombia). E-mail: franz.florez@utadeo.edu.co 


\title{
Landlord Chronotop in Documentary ¡Colombia Vive;
}

\begin{abstract}
Some of history analysis but more justification of what happened can be traced in a documentary, inspired by a landlord chronotop. Colombia's conflict in the Caracol and Semana, point of view teaches us an adventure topic with bad guys and equalizers, and put aside the Colombian social and premodern logic expressed in that violent way.
\end{abstract}

Keywords: Documentary, chronotop, Colombia, guerrillas, druglords, paramilitary groups, land lords society. 


\section{O cronotopo patriarcal no documentário ¡Colômbia Vive!}

\section{Resumo}

Um pouco de história e alguma justificação do presente podemse rastrear em um documentário, quando a narrativa é organizada a partir de um cronotopo patriarcal. O conflito na Colômbia, dito de forma melodramática por Caracol e Semana, torna-se em uma história de aventuras onde a emoção surge a partir das ações de confronto armado, ou da busca e captura de criminosos, mais do que pesquisar a lógica das relações pré-modernas que caracterizam a sociedade colombiana, e que manifestam-se violentamente e não somente servil.

Palavras-chave: Documentário, cronotopo, Colômbia, guerrilha, narcotráfico, paramilitares, sociedade senhorial. 
El documental ¡Colombia Vive! 25 años de resistencia. Memorias de un país sin memoria (2008) cuenta lo que, se supone, fueron los hechos más adversos que afrontó Colombia entre 1982 y 2007. El documental, producido por Caracol TV y la Revista Semana, está dividido en seis capítulos (Euforia, Terror, Lucha, Confusión, Ilusión, Ansiedad) y una recapitulación folclórica y optimista (Alegría).

En el presente texto se trata de mostrar cómo el concepto de cronotopo de Mijail Bajtin, creado para estudiar las formas del tiempo en la novela y, más aun, comprender cómo se estructuraban los géneros literarios, puede brindar una comprensión sobre la selección y edición de hechos noticiosos que constituyen esos "25 años de resistencia".

\section{UN Vistazo A LO QUE CUENTA EL DOCUMENTAL}

La euforia (1982-1984, 43 minutos) comienza mostrando las reacciones nacionales e internacionales respecto al premio Nobel de Literatura otorgado a Gabriel García Márquez, pero se concentra realmente en el proceso de paz del gobierno Betancur (1982-1986) con las guerrillas, el auge del narcotráfico y la indiferencia social con respecto a la exhibición de la fortuna de los capos del narcotráfico, el surgimiento de la Unión Patriótica por la tregua con las FARC, la guerra a las drogas con fumigaciones, algunas detenciones y decomisos, y finaliza con el asesinato del ministro de Justicia Rodrigo Lara.

En El terror (1984-1989, 43 minutos) se destaca la guerra contra la extradición por parte de los llamados extraditables, la toma y contratoma del Palacio de Justicia, la erupción del Volcán del Ruíz y la desaparición de
Armero, el genocidio de los militantes de la Unión Patriótica y de izquierdistas por parte de las autodefensas, la guerra del Cartel de Medellín que llegó a las ciudades, la dejación de armas por parte del M-19 y culmina con el asesinato de Luis Carlos Galán en campaña presidencial.

La lucha (1989-1994, 19 minutos) muestra en forma paralela el cambio de Constitución Política luego de la Asamblea Nacional Constituyente; la entrega, fuga y persecución de Pablo Escobar, que acaba con el narcoterrorismo pero no con el narcotráfico, negocio que, dice el documental, es tomado por guerrillas y paramilitares.

En La confusión (1994-1998, 29 minutos) se destaca la elección de Ernesto Samper con dineros del Cartel de Cali, y el asesinato de Álvaro Gómez en medio del escándalo de la financiación mafiosa de la campaña a la presidencia. Por su lado, los paramilitares se extienden por todo el país, $y$, por medio de masacres, llevan al desplazamiento de miles de familias, mientras la FARC da golpes contundentes a bases militares y toma prisioneros que luego durarán años en la selva. Termina el capítulo con niños y jóvenes que han sufrido mutilaciones por minas quiebrapatas, puestas por la guerrilla en zonas de cultivo de coca.

La ilusión (1998-2002, 29 minutos) comprende el gobierno de Andrés Pastrana centrado en el proceso de paz con la guerrilla de las FARC. Aparece una breve intervención del jefe paramilitar Carlos Castaño, quien dice que el país se le está entregando a la guerrilla, pero las acciones de sus efectivos no ocupan mayor espacio del capítulo. En cambio sí lo hacen las imágenes de policías 
y soldados en cautiverio, así como de civiles entre los que se cuenta a la precandidata presidencial Ingrid Betancourt. Secuestros masivos y atentados dan fin al proceso de paz. El capítulo termina con el asesinato del humorista Jaime Garzón.

La Ansiedad (2002-2007, 30 minutos) se centra en el recuento de la reconquista militar del país por intermedio de la fuerza pública, auspiciada por el gobierno de Álvaro Uribe y la financiación de Estados Unidos. Paralelo al repliegue de la guerrilla, se da el proceso de desmovilización de los paramilitares, en el que el papel de las víctimas queda relegado ante el despliegue que se le da a la disminución del conflicto armado ("la seguridad") y a los positivos indicadores económicos. Viene la reelección del presidente, y se abre espacio para hablar, por primera vez en todo el documental, de las víctimas, dado el descubrimiento de fosas comunes merced a la confesión de algunos jefes paramilitares. Se presenta también el destape de los vínculos de políticos con paramilitares, el pulso entre el gobierno y los familiares de secuestrados por un intercambio humanitario, el escape de algunos secuestrados y la muerte de otros en cautiverio. Finaliza con la incertidumbre de un lustro, o más, que llevan los secuestrados.

En la segunda parte del capítulo de cierre, hay una selección de "noticias positivas" agrupadas bajo el título de La alegría (1982-2007, 17 minutos). Su existencia se explica con el argumento de que "la resistencia frente a la adversidad ha generado un indeclinable deseo de superación" (¿?). Se mezclan sin orden cronológico fiestas, carnavales, éxitos de artistas o triunfos deportistas en el exterior, y los testimonios de economistas que hablan del mejoramiento de los indicadores macroeconómicos y de las condiciones de vida de los sectores populares.

Se trata de un cuarto de siglo que avanza en forma lineal del pasado (1982) hacia el presente de ese entonces (2007), con excepción del "anexo" La alegría. En el documental, el cambio de episodio está definido por una serie de actores (legales, ilegales), que producen cambios en la supuesta rutina ( $i$ ?) del país. Pero "Colombia" es en realidad, no el conjunto de la población, sino la "clase dirigente" de políticos, empresarios, periodistas y militares que, según el nombre mismo del documental, sobreviven como unidad a diferentes estados anímicos (euforia, confusión, ilusión y alegría), contrarrestados por dos episodios épicos (la lucha y, parcialmente, la ansiedad) y otro idílico (la alegría).

Pero, ¿realmente hay un cambio o varios a lo largo de un cuarto de siglo? El periodista Caballero y el analista político Gómez Buendía coinciden al afirmar que en Colombia el tiempo no avanza, es cíclico e incluso estático (Caballero, 1996, p. 2; Gómez, 2011). Porque no hay una concepción moderna ni en la "clase dirigente" ni en los dirigidos. En el libro No nacimos pa' semilla (1990) y en la película Rodrigo D: no futuro (1990) el tiempo es antimoderno, no tiene perspectivas de cambio o progreso, no hay antes o después, sólo un presente que debe ser vivido con intensidad; para el caso de los jóvenes de zonas urbanas marginales, puesto que eso lo hace más durable. Son conciencias de jóvenes que iban de los 12 a 20, o 25 años de edad en la década de 1980 y 1990, que encontraron en el viaje a la muerte una forma de participar, fugazmente, de esos bienes materiales con los que se identificaba el 
afecto, el reconocimiento y el agradecimiento a la familia.

En la narrativa de ¡Colombia Vive!, ese cambio parece entenderse como la mera sucesión de hechos noticiosos. No es una polifonía de voces recogidas por el documental, se trata de un sermón monológico, para usar la terminología de Bajtin. No hay una reflexión, de esos actores enfrentados, sobre el papel o rol que cumplen. Lo que aparecen son justificaciones de tipo político, en un contexto de exhibición mediática.

Es el caso de una ingenua periodista, que le pregunta a quemarropa al comandante guerrillero Pedro Antonio Marín, si ha cometido crímenes (secuestros, tráfico de cocaína, asesinato de soldados), lo cual él niega y justifica en el contexto de guerra. Al capo Gonzalo Rodríguez Gacha, se le pregunta si sus dineros son "calientes", él responde que lo único que ha hecho es brindar empleos y ayuda a los necesitados, y que los que ocuparon u ocupan la presidencia o la dirección de la institucionalidad económica, se autojustifican al seleccionar los hechos que los muestran como los indicados para el momento histórico que les tocó en suerte. En el documental, el género discursivo periodístico de la entrevista, a quienes tuvieron o tienen roles de poder, no lleva a un autoexamen de los sujetos, sino a la justificación de su posición social, que les da la posibilidad de tomar decisiones sobre la vida de otros. Esos otros son las víctimas no reconocidas que no son entrevistadas o cuyos puntos de vista no aparecen en el documental.

El contraste es notorio cuando se escuchan las declaraciones de otros periodistas y analistas políticos, que no ocuparon posiciones de poder (Alonso Salazar, Germán Castro, Claudia López), y que denuncian las contradicciones sociales que sustentan los conflictos que son convertidos en episodios noticiosos. El narcotráfico es visto (a partir de lo dicho por Salazar) no sólo como ostentación de mal gusto, tráfico ilegal y una criminalidad exacerbada para sostenerlo, sino también como el ascenso de unos valores y unas estéticas populares que fueron marginales y marginalizadas, hasta que tuvieron el respaldo económico para hacerse públicas. De igual forma, los esfuerzos de la policía por acabar con los cultivos de marihuana se ven (en el contexto aportado por Castro) como inocuos, cuando se recuerda que sólo se dejó de sembrar en Colombia porque en Estados Unidos se comenzó a cultivar o iniciaron con drogas más adictivas o fuertes. En cuanto a la parapolítica, la narración noticiosa muestra unos elegantes personajes (otrora comandantes paramilitares) que van al Congreso, y si bien reconocen que hubo crímenes, los justifican pidiendo que les agradezcan porque salvaron al país del comunismo. Mientras que la analista López plantea que la forma de hacer política incluyó la criminalidad, y que esos señores de la guerra no son cínicos, sino que vienen a pasar factura por sus servicios, esos servicios solicitados por los políticos para ser elegidos de manera "legal".

Para buscar algo de orden en esa esquizofrenia del documental, que, por un lado, narra con voz en off y de manera audiovisual que el personaje "Colombia" (la clase dirigente), con una identidad acabada o definida, resiste al conflicto armado promovido por diversos actores (guerrilla, paramilitares, narcotraficantes); por otro lado, incluye voces que nos llevan a pensar que el concepto 
de resistencia no es el más adecuado para describir una sociedad inacabada, dividida, profundamente desigual y con una jerarquía o clase dirigente que hace pactos con el diablo o que mantienen exclusiones para preservar sus privilegios y seguridad personal. Pareciera no una resistencia contra adversidades externas al país, sino contra la posibilidad de superar esos conflictos que definen, precisamente, lo desigual y autoritario que es el país. Para ahondar en esa hipótesis es necesario apelar a unas herramientas metodológicas brindadas por Bajtin, para comprender por qué es tan importante lo que se narra, como los principios que organizan el cambio (tiempo) y su expresión espacial, vista a través de las acciones que se muestran.

\section{Del CRONOTOPO A LA}

\section{CONCIENCIA Y VICEVERSA}

Al entender el cronotopo como "la conexión esencial de relaciones temporales y espaciales asimiladas artísticamente en la literatura" (Bajtin, 1989, p. 237, énfasis agregado); el álgido problema metodológico de buscar una lógica narrativa, estrictamente histórica, que se diferencie de la literaria (Colmenares, 1987; Bermejo, 2002; Burke, 2007, pp. 182-187), pasa a un segundo plano. Porque el problema no es cómo se representan, fidedignamente o no, una serie de acontecimientos de manera narrativa (lo fantástico en la ficción literaria o la realidad de un documental o un texto histórico), sino cómo es que los posibles cambios en la sociedad o rutinas cíclicas (tiempo), que ocurren en unos escenarios actuados y actualizados (espacio), son asimilados creativamente en la literatura histórica. Lugares específicos presentados en el documental objeto del presente escrito (selvas, ciudades, campos sembrados de amapola o marihuana, canchas de fútbol, entierros de personajes glorificados o cuerpos masacrados de gente del común) pertenecen a un orden inteligible (del que ya hablaremos) y que se presentan atravesados por corrientes de cambio o restauración de un orden latente.

Para Hayden White, una versión histórica del cronotopo de Bajtin tiene que ver con "mapas mentales", "el espíritu de la época", "las estructuras de la hegemonía dominante" o el "modo de producción" (White, 2011, pp. 422-423). Dicho de otra manera, los principios que dan estructura, o vinculan, de determinada manera las motivaciones de los individuos con las acciones que los hacen partícipes o no de un "orden social".

La asimilación de lugares y diferentes ritmos de cambio pretenden ser abarcados por una conciencia única y unitaria (la del historiador o el documentalista, en un libro con miles de datos y cientos de páginas, o en evocadoras y ambiciosas narrativas audiovisuales), pero también por algunos de los que rinden testimonio en el documental: periodistas, presidentes, expresidentes, economistas. Los puntos de vista de la gente del común no son tomados en cuenta para hacer balances del proceso histórico vivido, aunque sí para dar su testimonio como víctimas o afectados por los hechos de violencia.

En ¡Colombia Vive!, "la verdad” sobre lo que pasó en esos 25 años se cree que puede ser vista simplemente: la "fuente" histórica es la imagen misma o las declaraciones de los "protagonistas". No resulta casual que la revista Semana (VV. AA., 2012), coautora del documental, al discutir el uso pedagógico de la historia, reseñe la desaparición 
de los cursos de historia en primaria y secundaria en la década de 1980 y reduzca la formación de la conciencia ciudadana sin memoria histórica al problema de una baja en el sentimiento patriótico.

Pero en un balance reciente sobre los debates en torno a "la verdad histórica", se entiende como una "fenomenología permanente de la conciencia, sin un saber absoluto posible" (Brauer, 2005, p. 37, énfasis en el original).

La forma monológica de percibir la conciencia y la verdad es sólo una de las formas posibles. Esta forma surge únicamente cuando la conciencia se sobrepone al ser y cuando la unidad de éste se sobrepone a la unidad de aquella. [...] Una interacción sustancial de conciencias es imposible de concebir con base en un monologismo filosófico, y por tanto es imposible un diálogo esencial. En realidad, el idealismo conoce tan sólo un tipo de interacción cognoscitiva entre conciencias: la enseñanza que posee un conocedor que posee la verdad a aquel que no la conoce y que está en el error, es decir, la relación entre el maestro y el discípulo $\mathrm{y}$, por consiguiente, un diálogo pedagógico. (Bajtin, 2012, p. 177)

Desde la fenomenología, se entiende la conciencia como una vivencia (creer o desear algo) dirigida al mundo (Botero, 2003), pero de lo que se hace fenomenología es de esa vivencia previa a la actitud natural de que el mundo simplemente se percibe por los sentidos, de una manera organizada. El problema de cómo me veo a mí mismo (o cómo se ve a sí mismo el personaje de una novela, o un individuo que se expresa en un documental) es el de cómo tomar conciencia de lo que soy para mí mismo. En esa experiencia de autoconciencia, se supone que al usar esa estructura intencional ("creo de un algo que soy yo, esto o aquello") el sujeto no depende de la relación que tenga con otros sujetos (Ávila, 2010, p. 189).

Sin embargo, cuando la comprensión (no el conocimiento) de mí mismo pasa por la comprensión de los otros, el "yo" no es un espacio idéntico a sí mismo, sino aquello que se da en sus relaciones con los otros. En la perspectiva de Husserl, la historia se da en la historicidad de las relaciones intersubjetivas, fundamento del llamado mundode-la-vida (Cristin, 2000, p. 69). Tal interpretación de la posición husserliana sobre la historia es comparable con la crítica de Bajtin, la forma monológica de percibir la conciencia, la verdad y, por ende, la manera de entender personajes (reales o ficticios) que reflexionan sobre sí mismos o sobre su rol dentro de una narración. Así como la conciencia del científico maneja probabilidades en constante revisión, el conocimiento artístico no pretende representar la verdad, sino tomar conciencia de los sistemas de valores que dan estructura a lo que consideramos indiscutible (Bajtin, 2012, pp. 483-484).

Esa conciencia a la que se refería Bajtin no era la vivencia intencional de la que trataba de dar cuenta la fenomenología. Porque no se trata de una intersubjetividad dada por la interacción entre conciencias ajenas al mundo social, pues en ese caso el dialogismo de Bajtin se entendería siguiendo la forma monológica que él mismo pone en cuestión. Esto es, que no se trata de que Bajtin denuncie la subjetividad, el individualismo o el 
aislamiento moderno de autores de novelas o de sus personajes, y que se haya de pasar a una intersubjetividad que permita una comprensión más variopinta o plural, pero igualmente objetiva o acabada del mundo.

En el dialogismo toda expresión puede entenderse como la continuación de un diálogo, por autónoma o completa que parezca. No es simplemente el uso (habla) de un sistema (lengua) ajeno al contexto social. El sujeto habla como representante y desde una clase social, un grupo profesional, una generación. Por ello, para efectos de comprender lo que se dice en el documental, interesa no sólo quién o cómo lo dice, sino para quién o en respuesta a qué lo hace. El narrador "neutro" que aparenta describir lo que muestran las imágenes supone unas preguntas y asume unos comentarios por parte del espectador (Bajtin, 2011).

Dicho sea de paso, el diálogo o dialogismo propuesto por Bajtin hacia finales de la década de 1920 supone cierta sensibilidad histórica en cuanto a reconocer a los otros, no simplemente como objetos de los que se habla o escribe (se historizan, se etnografian, se fotografían, se les trata paternalmente), sino también como sujetos con los que es posible hablar y cuestionar esa conciencia moderna y autosuficiente (Todorov, 1989; 2005).

Un enfoque análogo fue el que llevó a que, luego de variados intentos por escribir un relato definitivo de "La historia de La Violencia en Colombia", se optara por enfocarse en sucesos puntuales de violencia y sobre todo en cómo las víctimas y sus entornos familiares y sociales habían seguido sus vidas luego del hecho violento y su reconocimiento mediático pero pasajero (CNMH, 2013).
No se trata de entender la polifonía de voces gracias al texto, sino de que la construcción del texto se da gracias a las actividades no textuales que acompañan la llegada y aceptación de extraños en una comunidad o familia. No se trata tampoco de que la instancia textual resuelva algo del trauma de modernización o de conflicto, sino que es una manera de darle espacio a las voces que construyen una verdad polifónica e inaprensible, desde un relato puramente académico o de reparación institucional.

Ese tipo de narraciones o textos "conversados" y creados "a cuatro manos" tienden a insertarse en un contexto pedagógico alternativo, para el curso institucional normal de lo que es una educación ajena a conflictos sociales, o entendida como transmisora de conocimientos ya acabados. Esos otros tipos de textos, escritos o audiovisuales, buscan fomentar otra clase de diálogos no necesariamente racionales o argumentados, pues el tipo de contexto en el que se insertan es dinámico y puede acoger, así como marginar, de un momento a otro esos textos que buscan la heteroglosia.

\section{Colombia: 25 AÑ̃S DE RESISTENCIA DE LA SOCIEDAD PATRIARCAL}

El problema que presenta el documental, en términos narrativos, es que recoge un inventario de acciones, personajes, hechos y lugares sin preguntarse cómo se enlazan o desenlazan los nudos argumentales. Dicho de otra manera, cómo suceden o no los encuentros entre los actores a lo largo del tiempo, haciendo ciertas cosas y en unos lugares determinados. La sociedad señorial que nos define, y que se enmascara con el 
acatamiento formal del Estado de Derecho, permanece ausente en un documental que busca ser la "memoria de un país sin memoria". No hay cuestionamientos sobre quiénes son los que nos dirigen o quiénes somos los que nos dejamos dirigir de cierta manera, porque la forma de recordarlo legitima el presente (euforia patriótica de comienzos del 2008).

En el caso colombiano, parecería haber un exceso de acciones conflictivas ("las que Colombia resiste"), pero que no implican o llevan a encuentros o separaciones entre los protagonistas de esas acciones. El nudo argumental (el porqué del conflicto, si el narco se enfrenta al gobierno simplemente para preservar su negocio, si los paramilitares se enfrentan a la guerrilla porque ni el ejército ni la policía lo pudieron hacer), y su anhelado desenlace (el fin de la guerra, la paz) parece supeditado a una variante del cronotopo de ciudad provinciana. Es decir, en lugar de un rutinario vivir en torno a cuartos, calles, lugares de juego, compras, chismes de barrio, comidas, infidelidades, uniones ejemplares, rituales sagrados o profanos que se repiten cada año; el conflicto en Colombia produce noticias pero no acontecimientos, porque no hay confrontaciones de valores, de conciencias, entre los protagonistas del conflicto, quienes viven en una rutina cotidiana del defenderse (la grandilocuente "resistencia") y no para combatir y llegar a un desenlace del conflicto.

No se buscan ni se crean espacios para el encuentro más allá de los efímeros rituales folclóricos, en los que la alegría reemplaza la ciudadanía y las satisfacciones emocionales se hacer pasar como derechos.
Es un tiempo frenado por la constante búsqueda de la restauración de un orden premoderno, patriarcal, en el que la movilidad social, ni siquiera de los sectores excluidos o marginados, sino de la misma movilidad de sectores burgueses (Gutiérrez, 1997; 2005) es vista como una amenaza a la unidad provinciana que han legado los patriarcas de tiempo atrás. Más que la "oligarquía" (gobierno de los ricos para los ricos y por los ricos) que denunciaba Gaitán a mediados del siglo XX, o recientemente Gustavo Petro, alcalde de Bogotá, la síntesis narrativa que se desprende del cronotopo patriarcal, supone el no cuestionamiento de los privilegios que implica la pertenencia a un linaje (los Santos, los Lleras, los Samper, los Gómez, los Valencia, los López), y el asumir que esos privilegios no se ganan, se heredan dentro del simulacro de nobleza impostada propia de las élites latinoamericanas (Cf. Romero, 2001; Gutiérrez, 1997; 2005).

Esa concepción señorial del tiempo y el espacio implica a los súbditos de esos señores, así como una comprensión puramente formal e instrumental de la ley que "es para los de ruana". Porque al tratar de aplicarse la ley al congresista que conduce ebrio o al familiar del funcionario público o militar (la "palanca" o el "padrino") vienen a la boca expresiones como: "es que usted no sabe con quién está hablando". El privilegio tradicional (un derecho de linaje noble inventado) por encima del derecho que supuestamente nos iguala como ciudadanos es precisamente una de las características de una sociedad que asume como propios los valores coloniales, que extendieron en tiempo y espacio la sociedad feudal europea en tierras americanas. 


\section{UNOS EJEMPLOS PATRIARCALES}

El régimen señorial que se construyó en torno al hombre blanco heterosexual y católico de la zona andina, que impone y subsiste gracias a un sistema patriarcal de explotación que choca con la lógica del capitalismo emergente (Cf. Colmenares, 1979), se puede detectar en el documental ¡Colombia Vive! al comienzo del relato donde se hace referencia al mes de agosto de 1982. En su discurso de posesión, el presidente Belisario Betancur planteó unos diálogos de paz con los guerrilleros de la siguiente manera:

\footnotetext{
Colombianos, no quiero que se derrame una sola gota más de sangre colombiana, de nuestros soldados abnegados, ni de nuestros campesinos inocentes, ni de los obcecados, ni una sola gota más de sangre hermana, ni una sola gota más de sangre colombiana. (¡Colombia Vive!, capítulo La euforia).
}

Lo que nos recuerda el 13 de junio de 1953, cuando el General Gustavo Rojas Pinilla se dirigió por radio a la nación y tomó posesión del cargo después de su golpe de Estado ("de opinión"), y anunció: "No más sangre, no más depredaciones. No más rencillas entre los hijos de la misma Colombia inmortal" (Forero, 1990, p. 7).

Lo que se convertiría en la dictadura de Rojas Pinilla dio paso a un régimen bipartidista de relevo en el poder del gobierno conocido como Frente Nacional. El 7 de agosto de 1958, el líder conservador Laureano Gómez saludaba al líder liberal Alberto Lleras, otrora contrincante, para celebrar su posesión como presidente, gracias al acuerdo político al que se había llegado para detener la violencia bipartidista de la década inmediatamente anterior:

Con cuanta alegría, con que fervor tan íntimo, preconizamos la concordia entre los colombianos, habituados y estimulados a despedazarse los unos a los otros. ¡Cuanto más grato es que de nuestro labios salgan palabras de amistad, de fraternidad, de colaboración y simpatía y no amargas voces destinadas a encender rencores y a promover discordias estériles! Si se me permite una declaración de índole personal he de decir que en las postrimerías de mi vida encuentro profundamente satisfactorio contribuir a la rectificación de los viejos sistemas que solo desastres ocasionaron y dedicar por completo los débiles esfuerzos que aún me son posibles a la reconciliación nacional, que os tiene como su experto ejecutor.

(Gómez, 1958).

El mea culpa (mi culpa) del discurso que preconiza la concordia entre los colombianos viene de quien les "estimulaba a despedazarse los unos a los otros", pues el mismo Laureano Gómez, una década antes, planteaba la rivalidad política en términos de una cruzada religiosa de condena o salvación (Jiménez, 2012). Esto no se trata de decir que el político era el titiritero que movía a los individuos, sino que la forma de valorar al otro, al contrincante político (liberal, conservador o, especialmente, comunista), se daba desde el fundamentalismo religioso y el resentimiento heredado de las guerras civiles del siglo XIX, tanto de liberales como de conservadores.

Ese tiempo idílico del patriarca y sus sirvientes, o del pastor y su grey, se repite 
en una entrevista realizada en el 2007 para el documental ¡Colombia Vive! El reelecto presidente Álvaro Uribe nos recordaba que había asumido la presidencia en el 2002 para "enfrentar el problema de seguridad, porque lo que se observaba era que el crecimiento de las fuerzas terroristas no había desintegrado la nación, pero si ya había derogado el Estado". La culpa era de "los grupos guerrilleros, que habían originado todos los problemas, y a la reacción criminal de los paramilitares". Es decir que fuera del enfrentamiento armado no había problemas en el diseño de las instituciones o deficiencias en la garantía de los derechos a las mayorías. Un año después, en febrero de 2008, bajo el diciente título "Izquierda y derecha. Esa discusión en el continente es obsoleta, polarizante", afirmó Uribe Vélez, abogado de la Facultad de Derecho y Ciencias Políticas en la conmemoración de los 180 años de su Facultad:

De allí viene la tragedia que han padecido sindicalistas de nuestro país. Porque esas guerrillas marxistas, en nombre de la combinación de formas de lucha, penetraron sectores del movimiento sindical, de la política y del periodismo. Siguieron avanzando los terroristas frente a un Estado que tenía la equivocada concepción de que la civilidad era buscar el diálogo con los terroristas y no enfrentarlos. Y después llegaron los otros terroristas, los paramilitares, a competir en crueldad e hicieron lo mismo. Y asesinaban líderes sindicales acusándolos de ser colaboradores de la guerrilla y viceversa.

Se trata pues, de una aventura caballeresca que requiere de redentores, héroes o padres que restauren el orden patriarcal idílico interrumpido por la guerrilla. Con ello se deja de lado que, aparte del conflicto armado, ha habido movimientos sociales, crímenes de Estado, modelos económicos excluyentes e incapaces de generar industrias rurales, que han permitido, de paso, el genocidio político de la Unión Patriótica (Hoyos, 2008).

La versión uribista de la historia nacional está acorde con dos de los 100 puntos de su "Manifiesto democrático" de sus tiempos de candidato a la presidencia (2001). Allí declaraba que los retos del Estado eran "derrotar la politiquería y la corrupción" y que la relación del presidente con la de los ciudadanos era paternal: "Miro a mis compatriotas hoy más con ojos de padre de familia que de político". No es casualidad que, al comparar la manera como Monseñor Miguel Ángel Builes se veía a sí mismo en 1936 en su "Manifiesto de los prelados de Colombia al pueblo católico" con la manera como se reconoce en su autobiografía el expresidente Uribe, se encuentre que los dos se consideren padres salvadores de "almas" por quienes el pueblo eleva plegarias (Restrepo, 2012).

El tiempo idílico y estático de la sociedad señorial fue interrumpido por la guerra y los patrones de la mafia, que demandaban el respeto exclusivo de los patriarcas. Dos de esos patriarcas, los expresidentes Alfonso López Michelsen y Belisario Betancur, fueron confrontados por una hipótesis de prospectiva sobre Colombia, según la cual el país se define por un modo de organización social anómico, que no facilita la abundancia de bienes públicos. La hipótesis, llamada "el almendrón", se expresa en una política representativa que no funciona 
como mediadora del conflicto social, porque predominarían las racionalidades privadas sobre la colectiva. En otras palabras, se confía en los individuos por encima de las reglas de juego (en lo económico, lo político o lo social). Los expresidentes consideraron que "la colectividad colombiana, quizá a causa de su pobreza, fue durante todo el siglo XIX hasta comienzos del siglo que expira, una sociedad resignada, sumisa, obediente, pastoril, en donde hasta en el curso mismo de las guerras civiles se mantenía un cierto tono de gallardía, de caballerosidad, de solidaridad humana, muy distinta de la actitud hobbesiana del presente". En este sentido, se trataba de una convivencia premoderna, no de individuos regulados por normas de derecho, sino de costumbres atávicas donde lo cotidiano era mediado por rituales colectivos. La construcción y la disputa por lo público (incluidos derechos como la seguridad social, la educación o el trabajo) son ajenas a ese tipo de formación social.

En una narrativa histórica típica de la ilustración, la pregunta sería hacia la conformación de Estados-nación, sustentados en sujetos políticos conscientes de sus derechos y deberes, luego de superar diversos conflictos surgidos del sobrepaso de una vida pastoril y autoritaria y pasar a una de deliberación pública regulada por la representación política (Bermejo \& Piedras, 1999). Al preguntarse por qué no se han arraigado en Colombia los principios del Estado liberal (González, 2008) aunque el fenómeno es latinoamericano, como mostró con creces José Luis Romero (2001) - , la narración supone concentrarse en tratar de explicar el porqué de la existencia de más caudillos y salvadores (en Colombia, Venezuela, Cuba, Ecuador, Bolivia...) que constituciones que se mantienen por encima de las coyunturas sociales y económicas. El problema es que ese interés sociopolítico puede dejar de lado los aspectos de condensación de prácticas sociales y valores morales, hacia los que llama la atención el concepto de cronotopo, y que se traducen en acciones que se hacen visibles o se omiten en la narración.

Llama la atención la aparición reiterada de ciertas expresiones usadas por los expresidentes y el monseñor, al referirse al conflictivo "pueblo": "rencillas entre hijos", "soldados abnegados", "campesinos inocentes", "sociedad resignada, sumisa, obediente, pastoril", "campesinado humilde y benévolo", "soy vuestro padre", "miro a mis compatriotas con ojos de padre de familia". No se les habla a ciudadanos sino a hijos descarriados, a siervos católicos de la Constitución Confesional de 1886, pero sobre todo a sujetos definidos por su sometimiento a la autoridad del patriarca, que no están en capacidad de deliberar por sí mismos.

Por eso es que Pablo Escobar, y no Fidel o Carlos Castaño, va a ser quien encarne la maldad bíblica, porque al convertirse en patrón, el peón altera la lógica señorial según la cual el respeto o la dignidad han de heredarse. Ni siquiera comprarse como sería el caso de un orden burgués, en el que el individualismo y el mercado depuran en la competencia, los dignos de ser imitados o vistos como ejemplo (Gutiérrez, 1997).

Esa maldad del narco es la que se encarna en la guerrilla, según ese otro patrón que se hace pasar por patriarca, el expresidente Uribe Vélez: "la culebra está viva", ha dicho que la maldad bíblica encarnada en el comunismo y la guerrilla, no pueden alterar 
ese orden católico en el que, se sueña, alguna vez hubo un orden alterado por la guerra (Jiménez, 2012). Los paramilitares nunca amenazaron el orden patriarcal, pues eran la expresión armada del mismo, y por eso se veían como aliados contra el advenedizo "patrón del mal".

El cronotopo patriarcal viene a enfrentarse con el cronotopo del patrón. Y no porque este último conlleve a un cambio $\mathrm{u}$ oriente, en un nuevo sentido el paso del tiempo, sino porque implica hacer visible, que en el paso de las relaciones cuasifeudales de la hacienda a las capitalistas de la empresa, quedó por fuera el paternalismo que hacía las veces de los derechos humanos de los trabajadores, vistos todavía en 1999 por los expresidentes Betancur y López, en términos precapitalistas de obediencia y comportamiento pastoril.

Ese cambio de la lógica de la mansión (cronotopo del patriarca urbano, ahí está la Mansión Montecasino de los Castaño o los clubes de la élite) a la hacienda (cronotopo del poder rural: ahí está la Hacienda Nápoles de Escobar o el Ubérrimo de Uribe Vélez) está muy bien ejemplificado en el capítulo de La euforia, en el que Gonzalo Rodríguez Gacha le entrega a la gente del pueblo atados de billetes, mientras un policía ayuda a que la fila no se desorganice. $\mathrm{O}$ en los actos públicos en que la gente de los barrios marginales de Medellín, le agradece a un satisfecho Pablo Escobar la entrega de canchas deportivas con iluminación o barrios enteros para gente que vivía antes entre la basura. Los patriarcas habían dejado a su suerte a los descendientes de sus antiguos sirvientes, y los patrones habían encontrado en el narcopopulismo la respuesta a: cómo invertir sus fortunas en admiración y respeto en público. Porque de parte de las élites, reconocían Gacha y Escobar, habían sido solicitados para financiar sus campañas políticas o empresas quebradas, pero no a la luz pública. Esa poca resistencia a la financiación del estatus social de las élites con dineros ilegales, no aparece y no puede aparecer en la narrativa del documental, porque implicaría reconocer los encuentros y acuerdos, entre quienes se presentan en la narración noticiosa y documental pública, como enemigos acérrimos.

\section{¿EL CONFLICTO COMO ENCUENTRO O NUDO ARGUMENTAL?}

Esa élite de políticos, empresarios, periodistas, y militares (que conforman, según el documental, la Colombia recordable) resiste a los violentos, y se define por defender "el establecimiento", pero no por ser emprendedora en temas como el de industria, el comercio, o la inversión en la mejor preparación para el fortalecimiento del talento humano. En un mundo con valores medievales, en el que las élites (herederas de los criollos que se quedaron con los cargos de los españoles expulsados durante la independencia) le dejaron las regiones y las zonas rurales a los intermediarios: los patrones mafiosos, los jefes guerreros ilegales, los caciques electorales (García, 2010; 2011b).

El conflicto es público y, por ende, objeto de noticias, pero ¿a quién beneficia la estigmatización de los movimientos sociales y la redistribución del ingreso? En uno de los países más desiguales del mundo, eso es un asunto privado. 
Como no hay un proyecto de cambio del orden social patriarcal, las noticias puestas en el documental, se introducen y presentan desde un cronotopo del mundo milagroso y sorpresivo en el tiempo incierto de la aventura.

Así es, se vive en una constante aventura caballeresca, en la que lo único seguro es que algo o alguien nos permitirá trasladarnos en el mismo espacio nacional de desgracias (estalla un volcán y sepulta una población, un terremoto derrumba el techo de una iglesia sobre los fieles en Semana Santa, detonan un avión con cientos de pasajeros, medio país se queda sin energía, jóvenes desempleados asesinan policías por un par de miles de dólares) a un tiempo mítico de celebración en medio de la aventura: un partido de fútbol, el título mundial de un beisbolista, un reinado internacional de belleza o, por supuesto, el premio Nobel de literatura en un país que lee menos de un libro al año, y cuyo galardonado estaba exiliado del país (exilio provocado, en parte, por amenazas oficiales y paraoficiales al ser simpatizante de grupos de izquierda a mediados de la década de 1970), cuando recibió la notificación del premio en 1982.

Tanto los desastres como los hechos jubilosos (generalmente logros individuales de deportistas o artistas) no son buscados colectivamente, sólo parecen llegar de repente. Y por estar a la expectativa de ese instante que nos lleve a un tiempo fugaz de alegría, cuando el logro no se alcanza, la desilusión roza el paroxismo, porque ese escape del tiempo cíclico de la desesperanza no se cumple y la rutina provinciana de violencia y desigualdad debe ser nuevamente afrontada.
En ese sentido, resulta comprensible que el subcapítulo denominado La alegría (19822007) no se presente de manera lineal sino episódica. No importa la ubicación cronológica de una telenovela que fue bien acogida por el público o un partido de fútbol que generó euforia nacional; el antes o el después se borran en cuanto no tienen consecuencias en la vida cotidiana, sino que se presentan como cronotopos milagrosos, en los que sí se encuentra esa nación dividida y en conflicto. El entretenimiento, el espectáculo, y el carnaval no funcionan sólo como espacios para la expresión de quienes no detentan el poder económico, el militar y el político, sino también como el espacio en el que se condensa el "ser colombiano" pero sin las desigualdades ni las jerarquías, en apariencia, justificadas (para preservar la unidad provinciana patriarcal) y necesarias (para defender esos privilegios señoriales).

Es una alegría desligada de la épica que muestra el resto del documental. No hay festividades, laicas o clericales, que conmemoren victorias contra la adversidad. Es como si ese mundo de conflicto fuera paralelo al de la alegría, el humor y la celebración.

Esta despolitización del elemento festivo y carnavalesco en función de su aprobación patriarcal, se puede ver para el caso del asesinato del humorista Jaime Garzón, a quien se le permitía hacer de bufón de la corte y ser la conciencia crítica de la gente de a pie o del hombre de la calle. Garzón sabía que entretenía, pero también sabía que no podía cambiar la mentalidad premoderna. La temporalidad se definía por la revelación mítica de los personajes representados por él mismo: el lustrabotas, el vigilante, la muchacha del servicio, el taxista, el estudiante 
"mamerto", e incluso los militares que vivían todavía en la Guerra Fría (el "Quemando Central").

Es en esa temporalidad, no causal sino regida por el azar, que las crónicas de vida están supeditadas a las teleologías teológicas: salvación o condena como explicación. En ese sentido, las narraciones históricas ejemplares (como modelos a seguir o evitar), ya no giran en torno a la forma de gobernar en medio del conflicto, sino a la manera de educarse a partir de ejemplares hombres que han sido tocados por la providencia o la maldad. De ahí que, cuando los canales de televisión han tratado de contar la historia de los narcotraficantes y paramilitares, se ha presupuesto un cronotopo medieval para hacer comprensibles los hechos, el nudo de la trama y su desenlace. Esto sucede por ejemplo con "Escobar: el patrón del mal" y "Los Caínes", nombres que de entrada anuncian una condena, pero también una santificación o glorificación de quienes se les opusieron. El problema ha sido que en esas narraciones se ha visto que "los malos", además de cometer crímenes, tienen todo aquello que le está negado a la mayoría de la población: dinero, lujo, mujeres-trofeo, pero por sobre todo, y antes y después de cualquier posesión material o goce físico, el respeto (García 2011a, 2012); no importa si esto se sustenta en el miedo o el soborno.

Precisamente esto es lo que hace entrar en crisis el modelo patriarcal en la década de 1980. El enfrentamiento con la guerrilla pasa a un segundo plano, cuando los patrones del narcotráfico se enfrentan a los patriarcas del establecimiento, cuando el mal se enfrenta al bien. De ahí que resulte incómodo, para la narración, tratar de presentar en el mismo nivel los funerales de quienes se oponían al establecimiento, como Jaime Pardo Leal o Bernardo Jaramillo. Son muertos reclamados por los marginados, al igual que Pablo Escobar.

El asesinato del ministro de Justicia Rodrigo Lara en 1984, del candidato presidencial Luis Carlos Galán en 1989 o del eterno excandidato presidencial Álvaro Gómez en 1995, se presentan como magnicidios que conmueven "al país", es decir, al establecimiento político, al económico y al social. Igual ocurre con la forma como se presentan los secuestros de los familiares de la élite (Maruja Pachón, Francisco Santos, el hermano del presidente César Gaviria), en contraste con la manera como son vistos, paternal y cristianamente los soldados y policías retenidos por la guerrilla en la selva. Si hay muertos o secuestrados de primera, de segunda y hasta de tercera, es que no hay realmente una Colombia sino varias, y una de esas es la verdadera Colombia, las otras son anexos prescindibles a los que se les puede dedicar menos atención. En la aventura caballeresca, el corrupto es incluso menos dañino que el comunista, puesto que el primero reitera el modelo patriarcal (un pecado venial, ni siquiera un delito), mientras que el segundo lo pone en cuestión, $\mathrm{y}$, por eso, hasta puede ser condenado.

\section{Epílogo}

Para pasar de esa sociedad estamental a una menos estática, vale la pena comenzar por entender esos "25 años de resistencia" no como una cruzada contra los malos para restaurar una idílica sociedad pastoril, sino como la resistencia a reconocer los fundamentos de ese resentimiento, ese autoritarismo y esa indiferencia que se anulan en los momentos de "alegría". 


\section{REFERENCIAS}

Ávila, I. (2010). Reseña: Intersubjetividad: ensayos filosóficos sobre autoconciencia, sujeto y acción, ed. F. Cely, \& W. Duica. Ideas y Valores, 142, 184-197.

Bajtin, M. ([1937, 1973] 1989). Las formas del tiempo y del cronotopo en la novela. Ensayos de poética histórica. En Teoría y estética de la novela (pp. 237-409). Madrid: Taurus.

Bajtin, M. ([1952] 2011). El problema de los géneros discursivos. En Las fronteras del discurso (pp. 9-66). Buenos Aires: Las cuarenta.

Bajtin, M. ([1929, 1963] 2012). Problemas de la poética de Dostoievski. México: Fondo de Cultura Económica.

Bermejo, J. (2002). Explicar o narrar: la Historia como problema. En M. Cruz (Ed.), Hacia dónde va el pasado. El porvenir de la memoria en el mundo contemporáneo (pp. 52-72). Madrid: Paidós.

Bermejo, J, \& Pedro, A. (1999). Genealogía de la historia. En J. Bermejo, \& P. Piedras, Genealogía de la historia. Ensayos de historia teórica III (pp. 5-128). Madrid: Akal.

Botero, J. (2003) Fenomenología. En L. Hoyos, Lecciones de filosofía (pp. 311-331). Bogotá: Universidad Externado de Colombia-Universidad Nacional de Colombia.

Brauer, D. (2005). Introducción. Rememoración y verdad en la narración historiográfica. En M. Cruz y D. Brauer (Eds.), La comprensión del pasado. Escritos sobre filosofía de la historia (pp. 13-39). Barcelona: Herder.

Burke, P. ([1990, 2004] 2007). Historia y teoría social. Buenos Aires: Amorrortu.

Caballero, A. (1996) Quince años de mal agüero. 1981-1996 artículos de prensa. Medellín: La Hoja.
Centro Nacional de Memoria Histórica CNMH. (2013). ¡Basta ya! Colombia: memorias de guerra y dignidad. Bogotá: Centro Nacional de Memoria Histórica.

Colmenares, G. (1979) Historia económica y social. Popayán, una sociedad esclavista, 1680-1800. Medellín: La Carreta.

Colmenares, G. (1987). Sobre fuentes, temporalidad y escritura de la historia. Boletín Cultural y Bibliográfico, 10 (87), 3-18.

Colombia vive! Dir. Mauricio Gómez. FM Discos, 2008. DVD.

Cristin, R. (2000) Fenomenología de la historicidad. El problema de la Historia en Dilthey y Husserl. Madrid: Akal.

Forero, A. (1990) Los antecedentes del golpe de Estado. El 13 de junio de 1953. Un día con 3 presidentes: Urdaneta, Gómez y Rojas Pinilla.Credencial Historia.

García, M. (2 abril de 2010) Semana Santa y Bicentenario, El Espectador. Recuperado de http://www.elespectador.com/columna196436-semana-santa-y-bicentenario

García, M. (3 de junio de 2011). Plata para ser patrón, El Espectador. Recuperado de http://www.elespectador.com/impreso/ opinion/columna-275004-plata-ser-patron

García, M. (28 de octubre de 2011b). Colonización al revés, El Espectador. Recuperado de http://www.elespectador.com/ impreso/opinion/columna-308239-colonizacion-al-reves? $\mathrm{q}=$ impreso/opinion/ columna-308239-colonizacion-al-reves

García, M. (15 de junio de 2012). Historias de malos, El Espectador. Recuperado de http://www.elespectador.com/opinion/ columna-353432-historias-de-malos

Gómez, B. (2011). Decálogo para entender este país, El malpensante, 125. Recuperado de http://elmalpensante.com/index. php $?$ doc $=$ display_contenido $\&$ id $=2216$ 
Gómez, L. (7 de agosto 1958). Acerca del Frente Nacional, discurso ante el congreso. Recuperado de http://aels4276-laureanogomez.blogspot.com/

González, J. (2008) La revolución liberal ni siquiera ha llegado a Colombia. En J. Ocampo (Ed.), Historia de las ideas políticas en Colombia (pp. 377-406). Bogotá: Taurus.

Gutiérrez, R. (1997) La crítica a la aristocracia bogotana en Gabriel García Márquez y R. H. Moreno-Durán. En Provocaciones (pp. 173-200). Bogotá: Ariel.

Gutiérrez, R. ([2000] 2005) Estratificación social, cultura y violencia. Aquelarre, 85-98.

Hoyos, G. (2008). Prólogo. En J. Ocampo, Historia de las ideas políticas en Colombia (pp. 11-22). Bogotá: Taurus.

Jiménez, D. (2012). El apocalipsis y el idilio. En La restauración conservadora, 19461957. Bogotá: Universidad Nacional de Colombia.

López A., \& Betancur, B. (1999). Preámbulo. El despertar nacional. En H. Gómez (Comp.), ¿Para dónde va Colombia? (pp. 15-20). Bogotá: Tercer Mundo Editores.
Restrepo, A. (4 de noviembre de 2012). La parábola de Álvaro Uribe Vélez. El Espectador. Recuperado de http://www.elespectador.com/noticias/cultura/articulo385231-parabola-de-alvaro-uribe-velez

Romero, J. ([1970] 2001). El pensamiento político de la derecha. En Situaciones e ideologías en América Latina (pp. 281407). Medellín: Editorial Universidad de Antioquia.

Todorov, T. ([1982] 1989) La conquista de América. El problema del otro. México: Siglo XXI.

Todorov, T. ([1991] 2005) Nosotros y los otros. Reflexión sobre la diversidad humana. México: Siglo XXI.

VV. AA. 2012. La crisis de la historia. Semana, marzo 24. Versión electrónica http:// www.semana.com/nacion/articulo/la-crisishistoria/255378-3 [Consulta realizada en noviembre de 2013]

White, H. ([1987] 2011). El siglo XIX como cronotopo. En La ficción de la narrativa. Ensayos sobre historia, literatura y teoría, 1957-2007 (pp. 415-428). Buenos Aires: Eterna Cadencia. 